\title{
Effect of flavour manipulation on low and high- frequency waterpipe users' puff topography, toxicant exposures and subjective experiences
}

\author{
Wasim Maziak, ${ }^{1}$ Ziyad Ben Taleb (D) ,' Mohammad Ebrahimi Kalan (D) , \\ Melissa Ward-Peterson, ' Zoran Bursac, ${ }^{3}$ Olatokunbo Osibogun (D) ,' \\ Thomas Eissenberg ${ }^{4}$
}

\begin{abstract}
'Department of Epidemiology, Robert Stempel College of Public Health, Florida International University, Miami, Florida, USA

${ }^{2}$ Department of Kinesiology, College of Nursing and Health Innovation, University of Texas at Arlington, Arlington, Texas, USA

${ }^{3}$ Department of Biostatistics, Robert Stempel College of Public Health and Social Work, Florida International University, Miami, Florida, USA ${ }^{4}$ Department of Psychology, Center for the Study of Tobacco Products, Virginia Commonwealth University, Richmond, Virginia, USA
\end{abstract}

\section{Correspondence to} DrWasim Maziak, College of Public Health, Florida International University, Miami, FL 33199, USA;

wmaziak@fiu.edu

Received 4 March 2019 Revised 25 June 2019

Accepted 27 June 2019 Published Online First 20 July 2019

\begin{abstract}
Background Flavoured tobacco is one of the major factors behind the popularity of waterpipe (WP) smoking in the USA and internationally. The current study examined the impact of flavour manipulation on satisfaction, puff topography and toxicant exposure among high-frequency and low-frequency WP users. Method This cross-over study was conducted among 144 current (past month) WP smokers reporting WP smoking less than once a week (low-frequency users; $n=69$ ) or at least once a week (high-frequency users; $n=75)$ in the past 6 months. Participants attended two counterbalanced $45 \mathrm{~min}$ ad libitum smoking sessions that differed by flavour (preferred flavoured vs unflavoured tobacco), preceded by $\geq 12$ hours of tobacco use abstinence. Outcome measures included puff topography, expired carbon monoxide (eCO), plasma nicotine and subjective measures.
\end{abstract}

Results Both high-frequency and low-frequency WP users reported an enhanced smoking experience and greater interest in future use after smoking the flavoured compared with unflavoured tobacco ( $p<0.05$ for all). High-frequency users, however, were more keen on smoking the flavoured tobacco in the future, had higher puffing parameters in general compared with lowfrequency users $(p<0.05$ for all) and had no differences in eCO and plasma nicotine concentrations between the flavoured and unflavoured tobacco conditions ( $p>0.05$ for all). On the other hand, low-frequency users had significantly greater eCO and plasma nicotine concentrations following smoking the unflavoured compared with flavoured tobacco condition $(p<0.05$ for all).

Conclusions Our results indicate that removing flavours will likely negatively affect WP satisfaction and future use and that such an effect will be more pronounced among high-frequency compared with lowfrequency WP smokers.

\section{INTRODUCTION}

Waterpipe (WP) tobacco smoking (aka hookah) has become increasingly popular in the USA and globally, notably among young adults. ${ }^{12}$ Data from population surveillance of tobacco use in the USA show a high prevalence $(18.2 \%)$ of current WP use among young adults aged 18-24 years, second only to cigarettes $(19.6 \%))^{3}$ One of the main drivers of WP smoking popularity among young people has been the introduction of sweetened and flavoured
WP tobacco known as Maassel. ${ }^{4-6}$ While the majority of WP smokers believe that WP tobacco is less harmful than cigarettes, evidence continues to emerge about its addictive and health hazardous properties. $^{78}$ One WP smoking session exposes users to greater smoke volumes and higher levels of toxicants such as carbon monoxide (CO), nicotine and tar compared with a single cigarette smoking. ${ }^{9}$

Quantitative and qualitative studies show that flavoured WP tobacco is the main attractant for new smokers and a key component of the 'WP experience' in established smokers. In a study sample of adult WP smokers in the USA, factors related to flavoured WP tobacco such as the smoke's taste (80\%), smell (61\%) and smoothness (42\%) were the motivation to smoke WP for the majority. ${ }^{10}$ Data from young people in the USA show similar results; our team's recent discrete choice experiment among young WP smokers revealed that fruit-flavoured tobacco is a key factor influencing the demand for WP. ${ }^{11}$ This preference for flavours is also supported by testimonies of young WP smokers in the USA, where fruity flavours and pleasant aroma can disguise WP risk and support experimentation and use. ${ }^{12}$ However, to fully appreciate the population impact of any potential flavour-based policy and regulation, it is important to understand how flavour limitation will affect WP smokers at different smoking patterns (eg, highfrequency vs low-frequency users).

The US Food and Drug Administration (FDA) has recently (10 May 2016) extended its regulatory authority under the deeming rule to include WP products under the Family Smoking Prevention and Tobacco Control Act. ${ }^{13}$ Accordingly, the FDA Center for Tobacco Products now regulates the manufacture, import, packaging, labelling, promotion, sale and distribution of WP tobacco, charcoal, parts and accessories. ${ }^{14}$ Several reports identified flavour as a major attractant for WP smokers, especially among youth and young adults. ${ }^{15} 16$ Therefore, flavour regulation represents a priority for regulatory efforts by the FDA and other agencies to limit WP smoking among these populations. ${ }^{25} 17$ This creates the need for evidence to guide the FDA and other policy bodies to effectively regulate WP tobacco flavours. This study attempts to answer the question of whether a flavour is important for smoking experience and toxicant exposures in WP smokers at different smoking patterns (highfrequency vs low-frequency WP users). 
Table 1 Descriptive characteristics of the sample by smoking group status ( $N=144)$

\begin{tabular}{|c|c|c|c|}
\hline Baseline characteristics & $\begin{array}{l}\text { Low-frequency } \\
\text { users } \\
N=69\end{array}$ & $\begin{array}{l}\text { High-frequency } \\
\text { users } \\
\mathrm{N}=75\end{array}$ & $P$ value \\
\hline Gender & $\mathrm{N}(\%)$ & $\mathrm{N}(\%)$ & \\
\hline Male & $40(57.9)$ & $45(60.0)$ & 0.804 \\
\hline Female & $29(42.1)$ & $30(40.0)$ & \\
\hline \multicolumn{4}{|l|}{ Hispanic } \\
\hline Yes & $28(40.6)$ & $32(42.7)$ & 0.799 \\
\hline No & $41(59.4)$ & $43(57.3)$ & \\
\hline \multicolumn{4}{|l|}{ Race } \\
\hline White & $50(72.5)$ & $47(62.6)$ & 0.127 \\
\hline Black African/American & $14(20.3)$ & 14 (18.7) & \\
\hline Other & $5(7.2)$ & $14(18.7)$ & \\
\hline \multicolumn{4}{|l|}{ Education } \\
\hline High school or less & $2(2.1)$ & $5(8.0)$ & 0.237 \\
\hline $\begin{array}{l}\text { Some college or } \\
\text { associate degree }\end{array}$ & $48(69.6)$ & $52(69.3)$ & \\
\hline Bachelor's degree & $10(14.5)$ & $13(17.3)$ & \\
\hline $\begin{array}{l}\text { More than bachelor's } \\
\text { degree }\end{array}$ & $9(13.0)$ & $4(5.3)$ & \\
\hline
\end{tabular}

$\begin{aligned} & \text { Have you smoked } \\
& \text { cigarettes in the past } \\
& \text { year? }\end{aligned}$
\begin{tabular}{llll} 
Yes & $31(44.9)$ & $23(30.7)$ & 0.077 \\
No & $38(55.1)$ & $52(69.3)$ & \\
\hline
\end{tabular}

\begin{tabular}{|c|c|c|c|}
\hline $\begin{array}{l}\text { When did you start } \\
\text { smoking WP in a monthly } \\
\text { manner? }\end{array}$ & & & \\
\hline Within past 6 months & $12(17.4)$ & $1(1.3)$ & 0.001 \\
\hline $\begin{array}{l}\text { More than } 6 \text { months } \\
\text { but less than a year }\end{array}$ & $13(18.8)$ & $10(13.3)$ & \\
\hline More than 1 year ago & $44(63.8)$ & $64(85.4)$ & \\
\hline $\begin{array}{l}\text { What is the average } \\
\text { time you usually spend } \\
\text { smoking WP? (minutes) }\end{array}$ & & & \\
\hline$<30$ & $9(13.0)$ & $4(5.3)$ & 0.020 \\
\hline $30-60$ & $46(66.7)$ & $41(54.7)$ & \\
\hline$>60$ & $14(20.3)$ & $30(40.0)$ & \\
\hline
\end{tabular}

Where do you usually smoke WP?

\begin{tabular}{|c|c|c|c|}
\hline At home & $7(10.0)$ & $25(33.3)$ & 0.003 \\
\hline At a friend's & $20(28.1)$ & $19(25.3)$ & \\
\hline $\begin{array}{l}\text { In public places (eg, a } \\
\text { cafe, lounge, etc) }\end{array}$ & $42(60.9)$ & $31(41.3)$ & \\
\hline \multicolumn{4}{|l|}{$\begin{array}{l}\text { Do you usually share the } \\
\text { ame WP with others? }\end{array}$} \\
\hline Yes & $66(95.7)$ & $66(88.0)$ & 0.097 \\
\hline No & $3(4.3)$ & $9(12.0)$ & \\
\hline \multicolumn{4}{|c|}{$\begin{array}{l}\text { Which WP tobacco } \\
\text { roduced greater smoke?*}\end{array}$} \\
\hline Preferred flavoured & $27(58.7)$ & $33(82.5)$ & 0.044 \\
\hline Unflavoured & $14(30.4)$ & $4(10.0)$ & \\
\hline No difference & $5(10.9)$ & $3(7.5)$ & \\
\hline referred flavours & & & 0.230 \\
\hline Grape & $4(5.8)$ & $12(16.0)$ & \\
\hline Apple & $25(36.2)$ & $21(28.0)$ & \\
\hline Mint & $14(20.3)$ & $17(22.7)$ & \\
\hline Mixed flavours & $22(31.9)$ & $18(24.0)$ & \\
\hline Others & $4(5.8)$ & $7(9.3)$ & \\
\hline
\end{tabular}

Continued
Table 1 Continued

\begin{tabular}{|c|c|c|c|}
\hline Baseline characteristics & $\begin{array}{l}\text { Low-frequency } \\
\text { users } \\
\mathrm{N}=69\end{array}$ & $\begin{array}{l}\text { High-frequency } \\
\text { users } \\
\mathrm{N}=75\end{array}$ & $P$ value \\
\hline & Mean (SD) & Mean (SD) & \\
\hline Age & $21.66(3.01)$ & $21.96(2.93)$ & 0.536 \\
\hline $\begin{array}{l}\text { How many years ago } \\
\text { did you start smoking } \\
\text { WP for the first time in } \\
\text { your life (even one or } \\
\text { two puffs)? }\end{array}$ & $3.57(2.79)$ & $4.58(2.85)$ & 0.034 \\
\hline $\begin{array}{l}\text { During the past } 6 \\
\text { months, on average, } \\
\text { how many WPs (head/ } \\
\text { bowls) you smoke per } \\
\text { month? }\end{array}$ & $2.45(1.84)$ & $9.52(11.67)$ & $<0.001$ \\
\hline eCO bassline & $1.91(1.13)$ & $2.14(1.48)$ & 0.293 \\
\hline $\begin{array}{l}\text { Post smoking flavoured } \\
\text { tobacco weightt }\end{array}$ & $11.28(1.40)$ & $10.53(1.73)$ & 0.006 \\
\hline $\begin{array}{l}\text { Post smoking } \\
\text { unflavoured tobacco } \\
\text { weight† }\end{array}$ & $9.84(1.38)$ & $9.51(1.24)$ & 0.139 \\
\hline
\end{tabular}

Bold numbers indicate statistical significance at $p<0.05$

${ }^{*}$ Only 86 participants responded to this question.

tPresmoking weight of tobacco was $15 \mathrm{~g}$ for each smoking group.

WP, waterpipe; eCO, expired carbon monoxide.

\section{METHODS AND MATERIALS}

\section{Recruitment and inclusion criteria}

Details for the methodology of the present study have been described elsewhere. ${ }^{18}$ In brief, healthy WP tobacco smokers who smoked flavoured WP tobacco aged 18-30 years from the Miami metropolitan area were invited to participate in the study via flyers, word of mouth and online advertisements (eg, Craigslist). Interested participants were excluded if they reported any history of chronic health concerns or psychiatric conditions, regular use of prescription medications (other than vitamins or birth control), self-reported current use of more than five cigarettes/month or other tobacco/nicotine products $(>5$ times in the past month preceding the study) and pregnancy (confirmed by urinalysis) or breast feeding. Prior to participation in a WP smoking session, overnight tobacco smoking abstinence was confirmed by expired $\mathrm{CO}(\mathrm{eCO})$ of $\leq 5$ parts per million (ppm). Participants provided written informed consent and received US $\$ 150$ cash as compensation at the end of the study.

\section{Smoking groups}

For this study, participants were classified according to their smoking pattern as either low-frequency or high-frequency WP users. Current WP smokers (past 30 days) who smoked WP (head/bowls; the small bowl in which tobacco is contained and exposed to heat while smoking WP) less than once a week in the past 6 months were classified as low-frequency users and those who smoked WP at least once a week were classified as highfrequency users.

\section{Smoking sessions}

In this laboratory study, we used a two-condition cross-over design in which each of the two sessions involved smoking a WP ad libitum for up to $45 \mathrm{~min}$ that differed by tobacco (preferred flavoured vs unflavoured WP tobacco). The two sessions order were counterbalanced and separated by at least a 48-hour washout period to avoid carryover effects of the previous session. 
Table 2 Waterpipe smoking topography measures, $\mathrm{CO}$ and plasma nicotine by condition and smoking group status ( $\mathrm{N}=143)$

\begin{tabular}{|c|c|c|c|c|c|c|c|c|c|c|}
\hline & \multicolumn{5}{|c|}{ Flavoured } & \multicolumn{5}{|c|}{ Unflavoured } \\
\hline & \multicolumn{2}{|c|}{$\begin{array}{l}\text { Low-frequency users } \\
(n=69)\end{array}$} & \multicolumn{2}{|c|}{$\begin{array}{l}\text { High-frequency users } \\
(n=74)\end{array}$} & \multirow[b]{2}{*}{ P value* } & \multicolumn{2}{|c|}{$\begin{array}{l}\text { Low-frequency users } \\
(n=69)\end{array}$} & \multicolumn{2}{|c|}{$\begin{array}{l}\text { High-frequency users } \\
(n=74)\end{array}$} & \multirow[b]{2}{*}{$P$ value* } \\
\hline & Mean & SD & Mean & SD & & Mean & SD & Mean & SD & \\
\hline Total smoke time (min) & 42:54 & $7: 37$ & $42: 02$ & $8: 02$ & 0.509 & $40: 06 t$ & $9: 42$ & $40: 56$ & 9:05 & 0.599 \\
\hline Cumulative puffing time (min) & $4: 59$ & 3:14 & $6: 13$ & $3: 46$ & 0.037 & $4: 16$ & $2: 41$ & $5: 18+$ & 3:06 & 0.034 \\
\hline Average puff duration (s) & 3.08 & 1.27 & 3.68 & 1.77 & 0.023 & 3.05 & 1.22 & 3.51 & 1.5 & 0.060 \\
\hline Total inhaled volume (L) & 51.16 & 33.31 & 81.50 & 54.73 & $<0.001$ & 53.53 & 33.35 & 78.92 & 51.81 & 0.001 \\
\hline Average puff volume (L) & 0.57 & 0.35 & 0.78 & 0.42 & 0.001 & $0.66 t$ & 0.35 & 2.04 & 8.52 & 0.185 \\
\hline eCO boost (ppm) & 12.1 & 11.7 & 30.72 & 33.27 & $<0.001$ & $17.52 \dagger$ & 14.63 & 33.37 & 27.60 & $<0.001$ \\
\hline Nicotine boost (ng/mL) & 4.33 & 0.58 & 10.45 & 1.17 & $<0.001$ & $5.69 \dagger$ & 0.81 & 9.09 & 0.97 & 0.008 \\
\hline
\end{tabular}

Bold numbers indicate statistical significance at $p<0.05$

${ }^{*} P$ value indicates the significant difference between smoking groups within tobacco conditions.

tSign indicates a significant difference between flavoured and unflavoured for that smoking group $(p<0.05)$.

$\mathrm{CO}$, carbon monoxide; IPI, interpuff interval; eCO, expired carbon monoxide.

The most common tobacco-based brands were Al Fakher, followed by Starbuzz and Haze (table 1 details flavoured tobacco preferences of participants). Before each session, the WP head was filled with $15 \mathrm{~g}$ of the assigned tobacco preparation and covered with a perforated aluminium foil to separate the quicklighting WP charcoal briquette (35 MM Coconut Shell Instant Light charcoal; Starbuzz Tobacco) from the tobacco mixture. ${ }^{19}$ To maintain standardisation during the smoking sessions, only one type of WP device was used (Khalil Mamoon 27 in, Egypt).

\section{Outcome measures}

WP puff topography

A validated instrument was used to assess puff topography ${ }^{20} 21$ with software that converted pressure signals to air flow (mL/ sec) data, producing measures of total smoking time, cumulative puff time, average puff duration, interpuff interval, number of puffs, total volume inhaled and average puff volume.

\section{Plasma nicotine and eCO}

At each laboratory visit, blood was drawn twice within $10 \mathrm{~min}$ of the beginning and end of each session. Plasma nicotine was measured using gas chromatography-mass spectrometry. ${ }^{22}$ Nicotine boost was assessed by subtracting presession nicotine levels from postsession. We measured the eCO using breath $\mathrm{CO}$ monitor (Vitalograph, Lenexa, Kansas, USA) before the $45 \mathrm{~min}$ WP smoking session started and within 5 min after it ended, and eCO boost was measured similar to nicotine boost.

\section{Subjective measures}

The 10-item version of the Tiffany-Drobes Questionnaire of Smoking Urges (QSU-Brief) was adapted to WP smoking and rated on a 7-point Likert scale ranging from 0 (strongly disagree) to 6 (strongly agree). The QSU-Brief examines two nicotine dependence factors: factor 1 , 'a strong desire and intention to smoke' and factor 2, 'anticipation of relief from withdrawal'. ${ }^{23}$ The QSU was administrated pre-WP and post-WP smoking session. $^{24}$

We also used the 9-item Duke Sensory Questionnaire (DSQ) rated on a 7-point Likert scale ('not at all' to 'extremely'). The DSQ was developed to assess participants' sensory experience of the inhaled product (eg, How satisfying were the puffs?). DSQ was assessed post-WP smoking session. ${ }^{18}$
The 11-item Waterpipe Evaluation Scale (WES) was adapted from the cigarette literature $e^{25} 26$ and rated on a 7-point Likert scale ('not at all' to 'extremely'). The WES assesses participants' perception of the smoked WP (eg, reduce craving, satisfying, tastes good and makes you dizzy). ${ }^{18}$ The WES was administered post-WP smoking session. ${ }^{18}$

At the end of the second session, participants were asked to evaluate the amount of smoke produced after each session by responding to this question 'Which WP tobacco produced the greater amount of smoke during your smoking session?' with the following answer options (1) flavoured tobacco, (2) unflavoured tobacco and (3) no difference. Eighty-six participants answered this question. In addition, participants were asked, 'How interested are you in using the tobacco you just smoked again in the future?'. The question was administered on a Visual Analogue Scale ranging from 0 ('not at all') to 100 ('extremely') presented as a horizontal line on the computer. Sixteen participants answered this question by placing a mark on the line that corresponded to a number along the line.

\section{Data analysis}

Descriptive statistics for the study sample characteristics were summarised with means (M) and SD for all outcomes (ie, puff topography, plasma nicotine, eCO and subjective measures). $\mathrm{X}^{2}$ tests were performed to examine the differences in categorical descriptive variables by WP smoking group. Two-tailed paired sample t-tests were performed to examine the differences in puff topography outcomes by smoking group (low-frequency vs high-frequency WP users). Planned comparisons using twotailed paired t-test were employed to create the cross-smoking group comparisons for puffing parameters, eCO, plasma nicotine and subjective measures. One participant was missing puff topography data for both sessions due to the device malfunctioning, and 13 were missing data points for plasma nicotine due to the inability to draw blood samples. Statistical significance was inferred from $\mathrm{p}<0.05$. All analyses were conducted on IBM statistics SPSS V.22.

\section{RESULTS}

A detailed description of the smoking group's baseline characteristics is shown in table 1 . Among all participants $(n=144), 75$ 

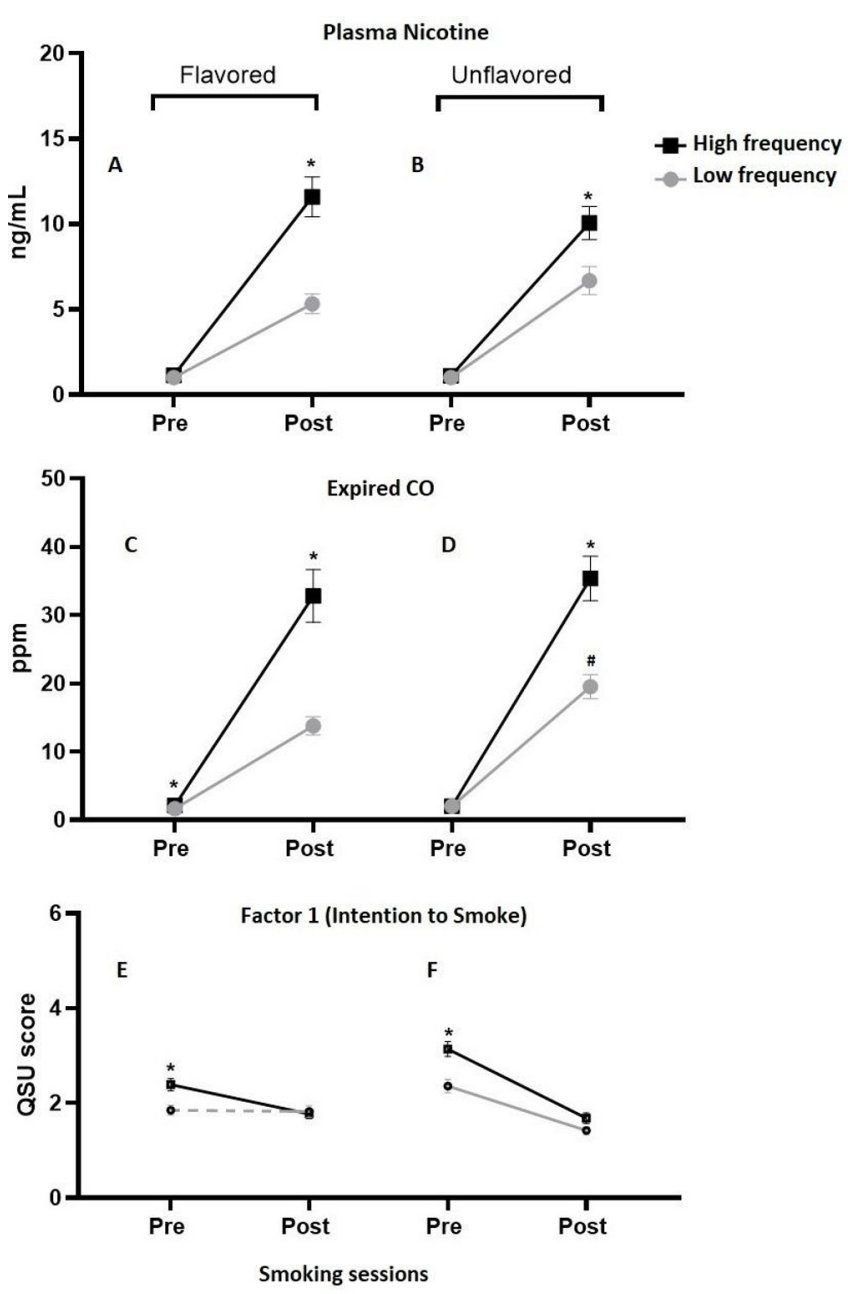

Figure 1 Mean $( \pm$ SEM) for plasma nicotine concentration in flavoured (A) and unflavoured (B) tobacco condition, eCO for the flavoured (C) and unflavoured (D) tobacco condition. Tiffany-Drobes QSU-Brief factor 1 (intention to smoke) for flavoured (E) and unflavoured (F) tobacco condition. While dashed line indicates no significant differences presmoking to postsmoking, solid lines show the significant differences. *Indicates significant differences between high and low-frequency WP users at that timepoints. \#Indicates a significant difference between flavoured and unflavoured for that smoking group $(p<0.05)$. CO, carbon monoxide; eCO, expired carbon monoxide; QSU, Questionnaire of Smoking Urges.

(52.0\%) were high-frequency users, and 69 (48.0\%) were lowfrequency users according to our adopted classification.

\section{WP puff topography}

Generally, high-frequency users had significantly higher puffing parameters compared with low-frequency users, which was more pronounced in the flavoured condition (details in table 2). There was no difference in puffing parameters between the flavoured and unflavoured tobacco condition within the high-frequency users' group $(\mathrm{p}<0.05)$. In contrast, low-frequency users had higher puff volume during the unflavoured tobacco session compared with the flavoured tobacco session $(0.66 \pm 0.35 \mathrm{~L}$ vs $0.57 \pm 0.35 \mathrm{~L}, \mathrm{p}<0.05$, respectively) (details in table 2 ).

\section{Plasma nicotine}

For both smoking groups, mean plasma nicotine concentration increased significantly from presmoking to postsmoking session in both flavoured and unflavoured tobacco conditions $(\mathrm{p}<0.05$ for all) (figure 1A, B). However, high-frequency users had greater plasma nicotine boost compared with low-frequency users during both flavoured $(10.45 \pm 1.17$ vs $4.33 \pm 0.58 \mathrm{ng} /$ $\mathrm{mL} ; \mathrm{p}<0.001)$ and unflavoured tobacco conditions $(9.09 \pm 0.97$ vs $5.69 \pm 0.81 \mathrm{ng} / \mathrm{mL} ; \mathrm{p}<0.001$ ) (table 2 ). Within the smoking groups, low-frequency users had a greater boost in plasma nicotine concentration during the unflavoured tobacco session $(5.69 \pm 0.81 \mathrm{ng} / \mathrm{mL})$ compared with the flavoured tobacco session $(4.33 \pm 0.58 \mathrm{ng} / \mathrm{mL}, \mathrm{p}<0.05)$, while such difference was not observed among high-frequency users (details in table 2).

\section{Expired carbon monoxide}

For both smoking groups, mean eCO levels increased significantly from pre to postsmoking session in both flavoured and unflavoured tobacco conditions ( $p<0.05$ for all) (figure $1 \mathrm{C}$, D). However, high-frequency users had a greater boost of eCO compared with low-frequency users during both flavoured $(30.72 \pm 33.27 \mathrm{vs} 12.1 \pm 11.7 \mathrm{ng} / \mathrm{mL} ; \mathrm{p}<0.001)$ and unflavoured tobacco conditions $(33.37 \pm 27.6$ vs $17.52 \pm 14.63 \mathrm{ng} / \mathrm{mL}$; $\mathrm{p}<0.001$ ) (table 2). Within the smoking groups, low-frequency users had a greater boost in eCO levels following the unflavoured tobacco session $(17.52 \pm 14.63 \mathrm{ppm})$ compared with the flavoured tobacco session $(12.1 \pm 11.7 \mathrm{ppm}, \mathrm{p}<0.05)$, while such difference was not observed among high-frequency users (details in table 2).

\section{Subjective measures}

For QSU-Brief, as shown in figure 1E, F, both low- and highfrequency users had a significant reduction in intention to smoke (factor 1) following the unflavoured tobacco smoking session, but only high-frequency users had a significant reduction following the flavoured tobacco smoking session ( $p<0.05$ for all). There were no significant changes for the anticipation of relief from withdrawal (factor 2) following both flavoured and unflavoured tobacco smoking sessions in both low and high-frequency users.

For the WES, following the flavoured tobacco smoking session, high-frequency users reported a greater reduction in craving compared with low-frequency users $(\mathrm{p}<0.05)$. Within smoking groups, both low and high-frequency users reported higher scores of product satisfaction, increased concentration, awake, less irritability and enjoyment of smoke sensation in the mouth and throat following smoking flavoured compared with unflavoured tobacco ( $p<0.05$ for all). On the other hand, both low- and high-frequency users reported higher scores of dizziness and nauseous following smoking unflavoured compared with flavoured tobacco ( $\mathrm{p}<0.05$ for all) (table 3 ).

For the DSQ, compared with high-frequency users, lowfrequency users reported higher scores for puff satisfaction, the similarity of product to smokers' own brand and for strengths of puffs on windpipe following the unflavoured tobacco smoking session ( $\mathrm{p}<0.05$ for all). Within the low-frequency users' group, smokers reported higher scores for puff liking, puff satisfaction and similarity of product to smokers' own brand following smoking the flavoured compared with the unflavoured tobacco $(p<0.05$ for all). Within the high-frequency users' group, smokers reported higher scores for strengths of puffs on the nose, windpipe and chest following the flavoured tobacco session compared with the unflavoured tobacco session $(\mathrm{p}<0.05$ for all) (table 3).

Participants' assessment of each tobacco condition's ability to generate smoke showed that $69.8 \%$ of participants believed that flavoured tobacco produced more smoke, while $20.9 \%$ believed 
Table 3 Postsession subjective responses for Waterpipe Evaluation Scale (WES) and Duke Sensory Questionnaire (DSQ) by condition and smoking group ( $\mathrm{N}=144)$

\begin{tabular}{|c|c|c|c|c|c|c|c|c|c|c|}
\hline & \multicolumn{5}{|c|}{ Flavoured } & \multicolumn{5}{|c|}{ Unflavoured } \\
\hline & \multicolumn{2}{|c|}{$\begin{array}{l}\text { Low-frequency users } \\
(\mathrm{n}=69)\end{array}$} & \multicolumn{2}{|c|}{$\begin{array}{l}\text { High-frequency users } \\
(n=75)\end{array}$} & \multirow[b]{2}{*}{ P value * } & \multicolumn{2}{|c|}{$\begin{array}{l}\text { Low-frequency } \\
\text { users }(n=69)\end{array}$} & \multicolumn{2}{|c|}{$\begin{array}{l}\text { High-frequency users } \\
(n=75)\end{array}$} & \multirow[b]{2}{*}{ P value* } \\
\hline & Mean & SD & Mean & SD & & Mean & SD & Mean & SD & \\
\hline \multicolumn{11}{|l|}{ WES measures } \\
\hline Satisfying & 4.26 & 1.50 & 4.52 & 1.38 & 0.284 & $3.30 t$ & 1.44 & 3.19 & 1.68 & 0.663 \\
\hline Taste & 4.58 & 1.36 & 4.76 & 1.49 & 0.453 & 2.55 & 1.49 & $2.22 t$ & 1.46 & 0.178 \\
\hline Dizzy & 3.06 & 1.40 & 2.80 & 1.56 & 0.301 & $3.51 \dagger$ & 1.46 & $3.19+$ & 1.57 & 0.214 \\
\hline Calm & 3.80 & 1.61 & 3.55 & 1.78 & 0.379 & $3.26 t$ & 1.55 & $2.91 \dagger$ & 1.69 & 0.194 \\
\hline Concentrate & 2.25 & 1.38 & 2.63 & 1.65 & 0.140 & $2.03 t$ & 1.16 & $2.00 t$ & 1.40 & 0.894 \\
\hline Awake & 2.13 & 1.34 & 2.45 & 1.74 & 0.290 & $1.96 t$ & 1.20 & $1.82 \dagger$ & 1.13 & 0.501 \\
\hline Reduce hunger & 2.09 & 1.40 & 2.19 & 1.60 & 0.692 & $1.83 t$ & 1.30 & $1.82 \dagger$ & 1.41 & 0.994 \\
\hline Nauseous & 1.93 & 1.16 & 1.88 & 1.33 & 0.821 & $2.41 \dagger$ & 1.54 & $2.41+$ & 1.63 & 0.999 \\
\hline Less irritable & 2.28 & 1.61 & 2.55 & 1.74 & 0.336 & $1.99+$ & 1.43 & $1.97 \dagger$ & 1.32 & 0.957 \\
\hline Sensation throat & 3.41 & 1.72 & 3.85 & 1.55 & 0.104 & $2.70 t$ & 1.69 & $2.68 t$ & 1.47 & 0.940 \\
\hline Reduced craving & 3.49 & 2.08 & 4.63 & 1.90 & 0.001 & $4.12 \dagger$ & 2.16 & $3.70 \dagger$ & 2.15 & 0.255 \\
\hline \multicolumn{11}{|l|}{ DSQ measures } \\
\hline Puff liking & 4.16 & 1.31 & 4.61 & 1.46 & 0.053 & $3.41 \dagger$ & 1.25 & 3.15 & 1.47 & 0.265 \\
\hline Puff satisfaction & 4.17 & 1.36 & 4.52 & 1.50 & 0.151 & $3.36 t$ & 1.27 & 2.88 & 1.51 & 0.041 \\
\hline Puffs high in nicotine & 3.67 & 1.12 & 3.60 & 1.25 & 0.738 & 4.00 & 1.32 & $3.82 \dagger$ & 1.45 & 0.453 \\
\hline Similar to own flavour & 4.36 & 1.61 & 4.93 & 1.87 & 0.053 & $2.68 t$ & 1.51 & 1.95 & 1.13 & 0.001 \\
\hline Strength of puffs on tongue & 3.71 & 1.30 & 3.68 & 1.40 & 0.894 & 3.68 & 1.32 & 3.30 & 1.48 & 0.106 \\
\hline Strength of puffs on nose & 3.13 & 1.43 & 3.04 & 1.42 & 0.705 & 3.03 & 1.38 & $2.91+$ & 1.43 & 0.601 \\
\hline Strength of puffs on back of mouth and throat & 3.96 & 1.39 & 3.79 & 1.46 & 0.478 & 3.72 & 1.34 & $3.66 t$ & 1.58 & 0.800 \\
\hline Strength of puffs on windpipe & 3.96 & 1.48 & 3.80 & 1.40 & 0.516 & 3.74 & 1.14 & $3.24 \dagger$ & 1.533 & 0.031 \\
\hline Strength of puffs on chest & 3.65 & 1.25 & 3.57 & 1.44 & 0.728 & 3.67 & 1.245 & $3.22 \dagger$ & 1.546 & 0.058 \\
\hline
\end{tabular}

Bold numbers indicate statistical significance at $\mathrm{p}<0.05$

${ }^{*} P$ value indicates the significant difference between smoking groups within tobacco conditions.

tSign indicates a significant difference between flavoured and unflavoured for that smoking group $(p<0.05)$

that unflavoured tobacco produced more smoke and $9.3 \%$ believed there was no difference $(p<0.05)$. Among participants who reported that flavoured tobacco produced more smoke, $55 \%$ were high-frequency users, and $45 \%$ were low-frequency users. For future intentions to use, participants were more interested in using flavoured tobacco versus unflavoured tobacco $(p=0.026)$, and this preference was more pronounced in highfrequency users compared with low-frequency users $(\mathrm{p}<0.05)$.

\section{DISCUSSION}

This clinical laboratory study is the first to investigate the impact of tobacco flavour manipulation on puff topography, toxicant exposure and subjective experience among WP smokers at different smoking patterns (high-frequency vs low-frequency WP users). The results show that both low-frequency and highfrequency WP users scored higher on satisfaction, and intention to use the product in the future following the flavoured tobacco session compared with the unflavoured tobacco session, although future use of flavoured products was more important to high-frequency users compared with low-frequency users. While some puffing parameters were more pronounced in the flavoured condition among high-frequency users, their overall associated exposures were not different between the two tobacco conditions. In contrast, low-frequency users had significantly greater eCO boost and plasma nicotine concentration following smoking the unflavoured compared with flavoured tobacco. Similar to the ban enforced on flavours other than menthol in cigarettes in the USA, it seems likely that restricting flavours in WP smoking could reduce initiation and interest in continued use. ${ }^{13}$ Our results indicate that banning flavours may affect WP satisfaction and future use but will have less immediate effects on smokers' exposures.

Our results are in line with previous research from cigarettes showing that smoking flavoured tobacco enhances the smoking experience. ${ }^{27}$ In our study, smokers not only enjoyed the flavoured tobacco more regardless of their smoking pattern but experienced fewer unfavourable effects with the flavoured compared with unflavoured tobacco. For example, participants felt more nauseous and experienced greater dizziness after smoking the unflavoured compared with flavoured tobacco. Some of that may be the result of increased exposure to CO, as participants had more $\mathrm{CO}$ exposure in the unflavoured tobacco condition compared with the flavoured tobacco condition as we discuss below.

Expectedly, puffing parameters followed the patterns of smoking, where high-frequency users had higher puffing parameters in general compared with low-frequency users regardless of flavour condition, and subsequently had higher nicotine and eCO boost. However, while high-frequency users did not experience differences in toxicant exposure between the two flavoured conditions, their low-frequency user's counterparts had significantly greater eCO boost and plasma nicotine concentration following smoking the unflavoured tobacco condition compared with the flavoured tobacco condition. It is likely that nicotine dependence was the main factor dictating smoking (puffing) behaviour in order to obtain the 'usual' dose of nicotine in high-frequency users, while low-frequency users were more attentive to their WP smoking experience, which involves 
the production of visible smoke with each puff. Several observations converge to make this a likely scenario. First, compared with flavoured tobacco, unflavoured tobacco had less humectant (a major source of particulate matter that is essential for the generation of visible smoke cloud). ${ }^{28}$ Second, participants in our study indicated that flavoured tobacco produced a greater smoke cloud compared with unflavoured tobacco. And third, a reduction in nicotine craving and plasma nicotine boost were more pronounced among high-frequency users compared with lowfrequency users. As such, it seems that low-frequency users had to take longer puffs to generate more smoke, aggravating the combustion process and consumption of tobacco leading to more $\mathrm{CO}$ and nicotine exposure, while high-frequency users' puffing (smoking) behaviour was mainly titrated towards achieving the usual nicotine dose.

This study has several limitations. Given the nature of the study's aims, that is, comparing flavoured and unflavoured tobacco conditions at different smoking patterns, blinding the participants to the two study conditions was not feasible. Another limitation is that the smoking groups were classified based on their WP smoking frequency in the past 6 months, which may not reflect their long-term smoking patterns. However, our analysis shows that on average the high-frequency WP users had a year longer WP smoking history compared with low-frequency users. Thus, our groups at least partially reflect smokers at different smoking patterns (high-frequency vs low-frequency WP users). Lastly, the effect of flavour on the likelihood of continued WP use in the future was examined among only 16 participants, which is a small sample to make a definitive conclusion about these results. However, even with this small number, the results were significant $(\mathrm{p}=0.026)$, indicating the likely direction of this result in larger studies.

Our results suggest that removing flavoured tobacco can be a promising regulatory avenue that will affect WP smokers' satisfaction and intention to use in the future regardless of their smoking frequency. However, the importance of flavoured tobacco to the smoking experience and continuation of smoking seems more pronounced among high-frequency users compared with low-frequency users. By contrast, the immediate effect of flavour limitation on smoking (puffing) behaviour and exposures seems less pronounced among high-frequency users compared with low-frequency users, likely due to the overriding effect of nicotine dependence on puffing parameters and subsequent exposures in this group. In summary, our results indicate that removing flavoured tobacco will likely negatively affect WP satisfaction and future use and that such an effect will be more pronounced among high-frequency compared with lowfrequency WP users.

\section{What this paper adds}

- One of the main drivers of waterpipe (WP) smoking popularity among young people has been the introduction of sweetened and flavoured WP tobacco known as Maassel.

- In order to explore the potential effect of flavour regulation on WP smokers of different smoking patterns (high-frequency vs low-frequency WP users), we need to understand how flavour limitation will affect WP smokers with different smoking frequency.

- Removing WP tobacco flavours will likely negatively affect WP satisfaction and future WP smoking among young people, and such an effect will be more pronounced among highfrequency WP users compared with low-frequency users.
Contributors WM and MEK conceptualised and designed the study, and drafted the initial manuscript. MEK, ZBT and ZB conducted data analysis. ZBT, MW-P, OO and TE contributed to the interpretation of data and critically revised the manuscript for important intellectual content. All authors approved the final manuscript as submitted.

Funding This study was funded by the National Institute on Drug Abuse at National Institutes of Health (NIH) under award R01 DA042477 and Fogarty International Center (FIC) under award R01TW010654-01. MW-P is currently supported by the National Institute of Minority Health and Health Disparities grant (U54MD012393-01) for FIU-RCMI. TE is supported by the NIH under Award U54DA036105 and the FDA CTP. TE is a paid consultant in litigation against the tobacco industry and is named on a patent for a device that measures the puffing behaviour of electronic cigarette users.

Disclaimer The content is solely responsibility of the authors and does not necessarily represent the views of the NIH or the FDA.

Competing interests No, there are no competing interests.

Patient consent for publication Not required.

Ethics approval This study was approved by the Institutional Review Board at Florida International University.

Provenance and peer review Not commissioned; externally peer reviewed. Data availability statement No data are available.

\section{ORCID iDs}

Ziyad Ben Taleb http://orcid.org/0000-0001-6894-5535

Mohammad Ebrahimi Kalan http://orcid.org/0000-0001-7709-5392

Olatokunbo Osibogun http://orcid.org/0000-0001-8902-4356

\section{REFERENCES}

1 Cobb C, Ward KD, Maziak W, et al. Waterpipe tobacco smoking: an emerging health crisis in the United States. Am J Health Behav 2010;34:275-85.

2 Maziak W, Taleb ZB, Bahelah R, et al. The global epidemiology of waterpipe smoking. Tob Control 2015;24(Suppl 1):i3-12.

3 Kasza KA, Ambrose BK, Conway KP, et al. Tobacco-Product use by adults and youths in the United States in 2013 and 2014. N Engl J Med 2017;376:342-53.

4 Akl EA, Jawad M, Lam WY, et al. Motives, beliefs and attitudes towards waterpipe tobacco smoking: a systematic review. Harm Reduct J 2013;10:12.

5 World Health Organization Study Group on Tobacco Product Regulation. Advisory note: waterpipe tobacco smoking: health effects, research needs and recommended actions by regulators. 2nd ed. Geneva, Switzerland: World Health Organization, 2015. ISBN: 9789241508469.

6 Breland A, Buchhalter A, Evans S, et al. Evaluating acute effects of potential reducedexposure products for smokers: clinical laboratory methodology. Nicotine Tob Res 2002;4(4):131-40.

7 Eshah NF, Froelicher ES, Knowledge FES. Knowledge, attitudes, beliefs and patterns of waterpipe use among Jordanian adults who exclusively smoke waterpipes. Eur J Cardiovasc Nurs 2018;17:85-92.

8 Waziry R, Jawad M, Ballout RA, et al. The effects of waterpipe tobacco smoking on health outcomes: an updated systematic review and meta-analysis. Int J Epidemiol 2017:46:32-43.

9 Primack BA, Carroll MV, Weiss PM, et al. Systematic review and meta-analysis of inhaled toxicants from waterpipe and cigarette smoking. Public Health Rep 2016;131:76-85.

10 Smith-Simone S, Maziak W, Ward KD, et al. Waterpipe tobacco smoking: knowledge, attitudes, beliefs, and behavior in two U.S. samples. Nicotine Tob Res 2008;10:393-8.

11 Salloum RG, Maziak W, Hammond D, et al. Eliciting preferences for waterpipe tobacco smoking using a discrete choice experiment: implications for product regulation. BMJ Open 2015;5:e009497.

12 Griffiths MA, Harmon TR, Gilly MC. Hubble bubble trouble: the need for education about and regulation of Hookah smoking. J Public Policy Mark 2011;30:119-32.

13 Food and Drug Administration, HHS. Deeming tobacco products to be subject to the federal food, drug, and cosmetic act, as amended by the family smoking prevention and tobacco control act; restrictions on the sale and distribution of tobacco products and required warning statements for tobacco products. final rule. Fed Regist 2016;81:28973-9106.

14 US Food and Drug Administration. Hookah tobacco (Shisha or waterpipe tobacco), 2016. Available: https://www.fda.gov/tobacco-products/products-ingredientscomponents/hookah-tobacco-shisha-or-waterpipe-tobacco [Accessed 29 April 2019].

15 Villanti AC, Johnson AL, Ambrose BK, et al. Flavored tobacco product use in youth and adults: findings from the first wave of the path study (2013-2014). Am J Prev Med 2017;53:139-51.

16 Feirman SP, Lock D, Cohen JE, et al. Flavored tobacco products in the United States: a systematic review assessing use and attitudes. Nicotine Tob Res 2016;18:739-49. 
17 US Food and Drug Adminstration. CTP-Supported tobacco regulatory research projects. Available: https://www.fda.gov/tobacco-products/research/ctp-supportedtobacco-regulatory-research-projects [Accessed on 6 June 2019].

18 Ben Taleb Z, Breland A, Bahelah R, et al. Flavored versus Non-Flavored waterpipe tobacco: a comparison of toxicant exposure, puff topography, subjective experiences and harm perceptions. Nicotine Tob Res 2018. doi:10.1093/ntr/nty131. [Epub ahead of print: 04 Jul 2018]

19 Eissenberg T, Shihadeh A. Waterpipe tobacco and cigarette smoking: direct comparison of toxicant exposure. Am J Prev Med 2009;37:518-23.

20 Shihadeh A. Investigation of mainstream smoke aerosol of the argileh water pipe. Food Chem Toxicol 2003:41:143-52.

21 Shihadeh A, Azar S, Antonios C, et al. Towards a topographical model of narghile water-pipe café smoking: a pilot study in a high socioeconomic status neighborhood of Beirut, Lebanon. Pharmacol Biochem Behav 2004;79:75-82.

22 Jacob P, Wu S, Yu L, et al. Simultaneous determination of mecamylamine, nicotine, and cotinine in plasma by gas chromatography-mass spectrometry. J Pharm Biomed Anal 2000;23:653-61.
23 Cox LS, Tiffany ST, Christen AG. Evaluation of the brief questionnaire of smoking urges (QSU-brief) in laboratory and clinical settings. Nicotine Tob Res 2001;3:7-16.

24 Maziak W, Rastam S, Ibrahim I, et al. CO exposure, puff topography, and subjective effects in waterpipe tobacco smokers. Nicotine Tob Res 2009;11:806-11.

25 Rose JE, Behm FM, Westman EC, et al. Dissociating nicotine and nonnicotine components of cigarette smoking. Pharmacol Biochem Behav 2000;67:71-81.

26 Malson JL, Pickworth WB. Bidis--hand-rolled, Indian cigarettes: effects on physiological, biochemical and subjective measures. Pharmacol Biochem Behav 2002;72:443-7.

27 Hersey JC, Nonnemaker JM, Homsi G. Menthol cigarettes contribute to the appeal and addiction potential of smoking for youth. Nicotine Tob Res 2010;12(suppl_2):S136 $-\$ 146$.

28 Brinkman M, Adetona A, Buehler S, et al. The effect of Humectant and Flavorant content on harmful and potentially harmful constituent emissions in mainstream waterpipe tobacco smoke. Society for research on nicotine and tobacco annual meeting 2018. Available: https://cdn.ymaws.com/www.srnt. org/resource/resmgr/conferences/2018_Annual_Meeting/65388_SRNT_2018_ Abstract_fin.pdf 